\title{
ARTICLE
}

\section{Organocatalytic atroposelective synthesis of axially chiral styrenes}

Sheng-Cai Zheng ${ }^{1}$, San Wu1, Qinghai Zhou1, Lung Wa Chung ${ }^{1}$, Liu Ye ${ }^{1} \&$ Bin $\operatorname{Tan}^{1}$

Axially chiral compounds are widespread in biologically active compounds and are useful chiral ligands or organocatalysts in asymmetric catalysis. It is well-known that styrenes are one of the most abundant and principal feedstocks and thus represent excellent prospective building blocks for chemical synthesis. Driven by the development of atroposelective synthesis of axially chiral styrene derivatives, we discovered herein the asymmetric organocatalytic approach via direct Michael addition reaction of substituted diones/ketone esters/malononitrile to alkynals. The axially chiral styrene compounds were produced with good chemical yields, enantioselectivities and almost complete $E / Z$-selectivities through a secondary amine-catalysed iminium activation strategy under mild conditions. Such structural motifs are important precursors for further transformations into biologically active compounds and synthetic useful intermediates and may have potential applications in asymmetric synthesis as olefin ligands or organocatalysts.

\footnotetext{
${ }^{1}$ Department of Chemistry, South University of Science and Technology of China, Shenzhen 518055, China. Correspondence and requests for materials should be addressed to B.T. (email: tanb@sustc.edu.cn).
} 
A xially chiral compounds in which the chirality originates from highly sterically hindered rotation along a chiral axis rather than a stereogenic centre with four different substituents have received much attention from chemists because of their widespread appearance in biologically active compounds and useful chiral ligands in asymmetric catalysis. Among the well-known axially chiral structures, most of the chiral axis is between two aromatic moieties as named biaryl atropisomers. Owing to the importance of this structural motif, the catalytic atroposelective construction of axially chiral biaryls has been intensively investigated ${ }^{1-6}$ and could be accessed by enantioselective oxidative/cross coupling of two aryl counterparts, ${ }^{7-13}$ asymmetric construction of an aromatic ring $^{14-20}$ and kinetic resolution/desymmetrization of biaryl compounds (Fig. 1a, left) ${ }^{21-36}$. However, in sharp contrast, the axially chiral styrenes bearing a chiral axis between a simple alkene and an aromatic ring have been rarely studied with respect to asymmetric synthesis and applications ${ }^{37,38}$. Although this type of atropisomer was firstly proposed to demonstrate a new concept of the memory of chirality by Kawabata et al. ${ }^{39}$ in 1991, the consequent investigations on synthesis or application of axially chiral styrenes remain underexplored ${ }^{40-42}$ (Fig. 1a, right). The main reasons are presumably attributed to the relatively low-rotation energy to racemization and the difficulty to control the enantioselectivity.

Inspired by elegant reports concerning the synthesis of axially chiral styrene-type derivatives ${ }^{43,44}, \mathrm{Gu}$ and co-workers ${ }^{45}$ developed an efficient enantioselective construction of axially chiral vinyl arenes from aryl bromide and hydrazones by using palladium catalysis, providing a pioneering example for the atroposelective catalytic synthesis of axially chiral styrene-type derivatives. It is well-known that simple styrenes are one of the most abundant and principal feedstock, and thus represent excellent prospective building blocks for chemical synthesis. Most interestingly, chiral olefins have been utilized to generate metal-olefin complexes for enantioselective transformations ${ }^{46-48}$. Therefore, the development of enantioselective synthetic approach to axially chiral styrenes becomes very attractive and highly desirable. Iminium activation ${ }^{49,50}$ has been successfully utilized to control the enantioselectivity at the $\beta$-position on the $\alpha, \beta$-unsaturated aldehyde (enal). Alkynals are known to be a challenging class of electrophiles in asymmetric catalysis because they would adopt different structures and geometry ${ }^{51}$. As such, in contrast to these widely reported iminium activated enal systems, the organocatalytic enantioselective transformation involving alkynal remains underexplored ${ }^{52-56}$. In this context, Wang and co-workers reported the elegant work $^{53}$ involving a domino iminium-allenamine process to control the stereoselectivity far from the $\beta$-position on the alkynal. To further extend the utility of alkynal in asymmetric synthesis and particularly perform a direct enantioselective reaction of nucleophilic addition to alkynal, we envision that the chiral allenamine intermediate in situ generated from the initial Michael addition of nucleophile to an iminium ion would then transfer the chiral information to control the axial chirality of the styrene derivatives (Fig. 1b).

In this scenario, several challenges would be encountered: (1) the atroposelective construction of axially chiral styrene compounds has rarely been investigated in asymmetric catalysis, (2) the selection of appropriate nucleophile to allow a compromise between reactivity and selectivity in the organocatalytic nucleophilic addition and the steric hindrance required to possess enough rotation energy to maintain the integrity of the chiral axis, (3) the choice of a suitable chiral organocatalyst to efficiently control $E / Z$ selectivity since in only one isomer may exist axial chirality. As part of our ongoing interest in asymmetric organocatalysis on construction of axially chiral compounds ${ }^{15,27,57,58}$, we describe herein the first organocatalytic atroposelective synthesis of axially chiral styrene compounds via direct Michael reaction of substituted diones/ketone esters/malononitrile to alkynals, providing a powerful and

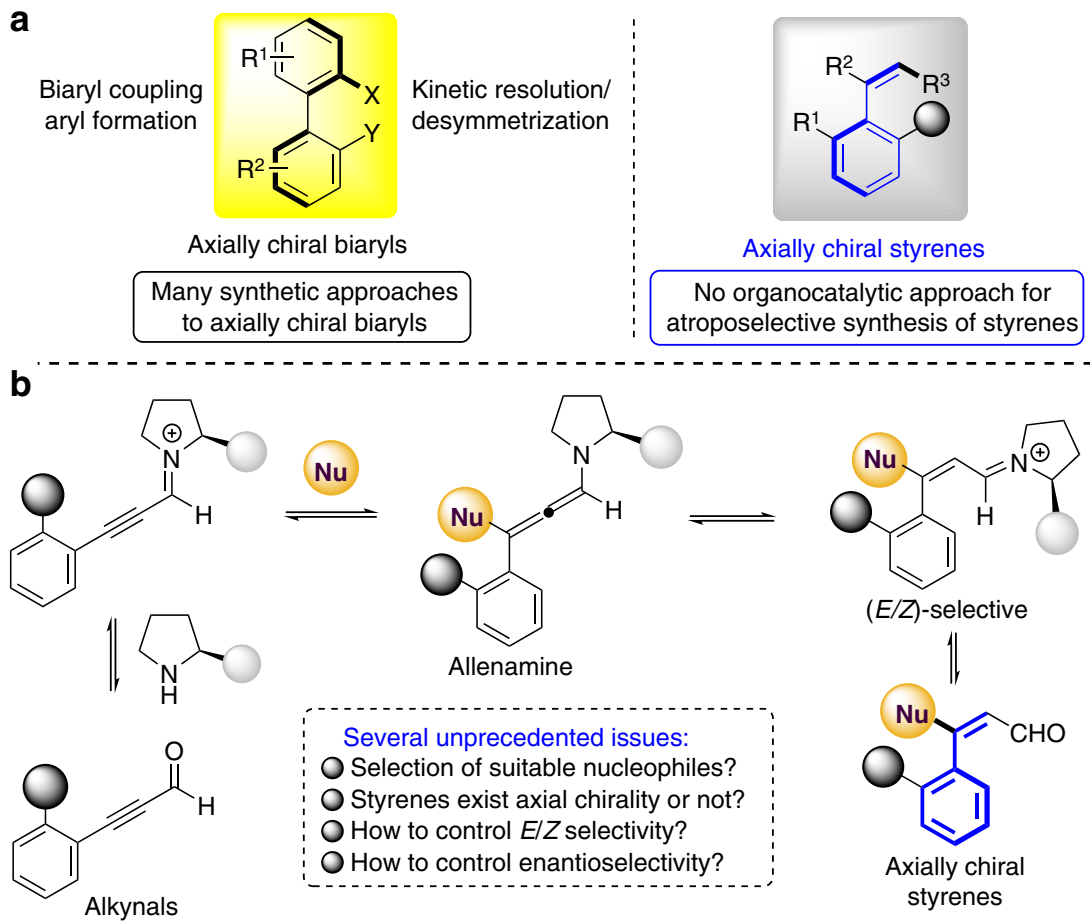

Figure 1 | Background introduction of axially chiral styrenes and our strategy. (a) The existing approaches for atroposelective synthesis of axially chiral biaryls and styrenes. (b) Our strategy for atroposelective synthesis of axially chiral styrenes. 


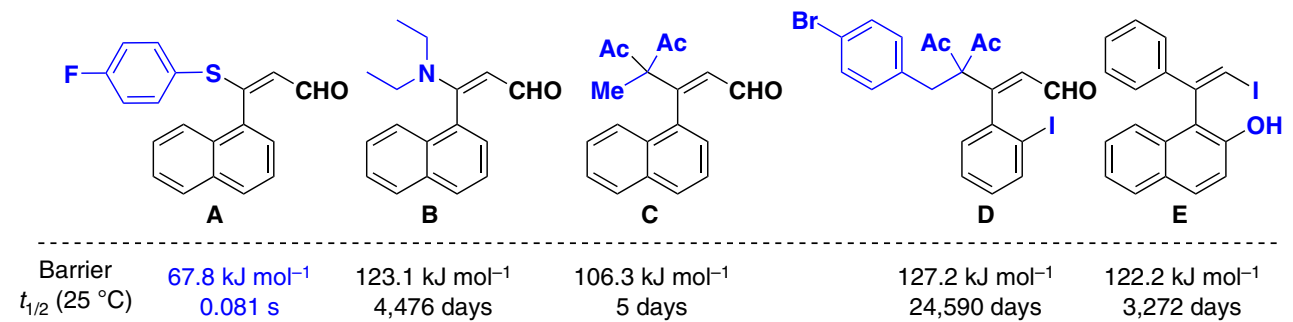

Figure 2 | Computed rotation barriers of several styrenes and their corresponding half-life. The above computed rotation barriers along the axial $\mathrm{C}-\mathrm{CAr}$ bond and their corresponding $t_{1 / 2}\left(25^{\circ} \mathrm{C}\right)$ were estimated by SMD M06-D3/6-31+ G*//M06-D3/6-31G* method. (See the computational details and Supplementary Figs 1-4).

\section{Table 1 | Optimization of the reaction conditions ${ }^{\star}$.}

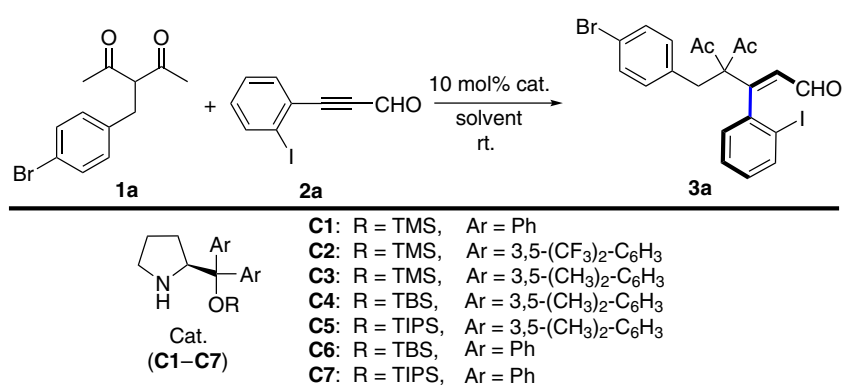

\begin{tabular}{|c|c|c|c|c|c|}
\hline Entry & Catalyst & $T\left({ }^{\circ} \mathrm{C}\right)$ & Solvent & Yield $(\%)^{\dagger}$ & ee $(\%)^{\ddagger}$ \\
\hline 1 & C1 & $\mathrm{rt}$ & $\mathrm{CHCl}_{3}$ & 74 & 65 \\
\hline 2 & C2 & rt & $\mathrm{CHCl}_{3}$ & Trace & $N D^{\S}$ \\
\hline 3 & C3 & $r t$ & $\mathrm{CHCl}_{3}$ & 93 & 65 \\
\hline 4 & C4 & $r t$ & $\mathrm{CHCl}_{3}$ & 97 & 83 \\
\hline 5 & $\mathbf{C 5}$ & $r t$ & $\mathrm{CHCl}_{3}$ & 54 & 90 \\
\hline 6 & C6 & rt & $\mathrm{CHCl}_{3}$ & 90 & 85 \\
\hline 7 & C7 & rt & $\mathrm{CHCl}_{3}$ & 54 & 86 \\
\hline 8 & C5 & $\mathrm{rt}$ & DCM & 95 & 90 \\
\hline 9 & C5 & rt & Toluene & 78 & 88 \\
\hline 10 & C5 (5 mol\%) & rt & DCM & 94 & 90 \\
\hline 11 & C5 (5 mol\%) & 0 & DCM & 55 & 94 \\
\hline 12 & C5 (5 mol\%) & -20 & DCM & Trace & $N D^{\S}$ \\
\hline $13^{\|}$ & C5 (5 mol\%) & 0 & DCM & 96 & 94 \\
\hline
\end{tabular}

*Unless otherwise stated all reaction were performed by using $\mathbf{1 a}(0.05 \mathrm{mmol}), \mathbf{2 a}(0.055 \mathrm{mmol}, 1.1$ equiv), catalyst $(10 \mathrm{~mol} \%)$ and solvent $(0.5 \mathrm{ml})$ at room temperature $(\mathrm{rt})$ for $24 \mathrm{~h}$

† Isolated yield.

tDetermined by chiral stationary HPLC.

Not determined.

IILiOAc $(0.025 \mathrm{mmol})$ as additive.

straightforward synthetic route toward substituted styrene derivatives. Such structural motifs are important chiral components for further transformations into biologically active natural products and pharmaceutical compounds and may have potential application in asymmetric catalysis as olefin ligands or organocatalysts.

\section{Results}

Discovery of configurationally stable axially chiral styrenes. Motivated by Kawabata's pioneering discovery, we synthesized the compound $\mathbf{A}$ through Michael addition reaction and imagined that in such compound may exhibit axial chirality due to the restricted rotation between double bond and the directly attached naphthyl group (Fig. 2). Disappointedly, compound A displays no axial chirality based on the chiral stationary high-performance liquid chromatography (HPLC) analysis and computed relatively low-rotation barrier $\left(67.8 \mathrm{~kJ} \mathrm{~mol}^{-1}\right)$, corresponding to a first-order half-life $\left(t_{1 / 2}\right)$ of $0.081 \mathrm{~s}$. To further increase the rotation barrier for an axially chiral styrene compound, we synthesized three styrene-type compounds B, C, $\mathbf{D}$ and $\mathbf{E}$ with more bulky nucleophiles. We are pleased to find that these compounds show apparently axial chirality and much larger rotation barriers (Fig. 2). Notably, the compound $\mathbf{D}$ possess high rotational energy barrier around $127.2 \mathrm{~kJ} \mathrm{~mol}^{-1}$, clearly indicating that the substituted styrene-type compounds might be stable for asymmetric synthesis and other transformations. On the base of racemization experiments and kinetics of racemisation of an enantiomer, the rotational barrier of compound $\mathbf{D}$ was $117.9 \mathrm{~kJ} \mathrm{~mol}^{-1}$ under the solvent of chloroform at $61^{\circ} \mathrm{C}$ (for details, see Supplementary Note 1).

Optimization of reaction conditions. After confirmation of the axially chiral styrenes (Fig. 2, compounds B, C, D, E), we turned our attention to develop an atroposelective synthesis of chiral styrenes. Our initial investigations focused on evaluating the reaction between 3-(4-bromobenzyl)pentane-2,4-dione 1a and 
Table 2 | The substrate scope with respect to alkynals ${ }^{\star}, \dagger$,

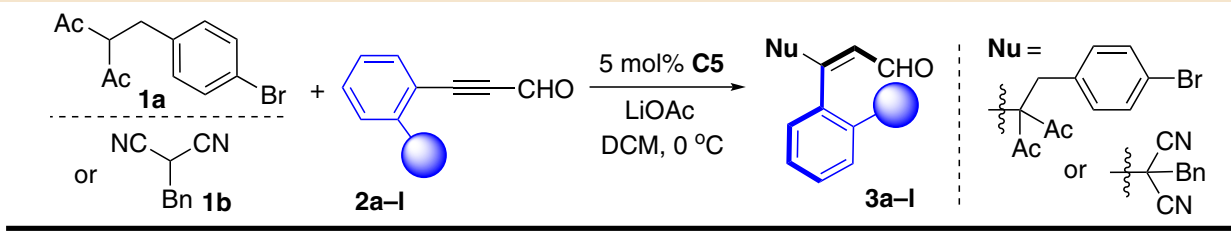<smiles>CC(C)(Cc1ccc(Br)cc1)C(=CC=O)c1ccccc1I</smiles>

$3 a$ $96 \%$ yield, $94 \%$ ee<smiles>CC(C)(Cc1ccc(Br)cc1)C(=CC=O)c1ccccc1C(F)(F)F</smiles>

3b $95 \%$ yield, $90 \%$ ee<smiles>CC(C)(Cc1ccc(Br)cc1)C(=CCO)c1ccccc1S(=O)(=O)c1ccccc1</smiles>

3c $40 \%$ yield $82 \%$ ee $(Z / E=96 / 4)$<smiles>CC(C)(C)C(=CC=O)c1cccc2ccccc12</smiles>

3d

$99 \%$ yield, $92 \%$ ee<smiles>C=C(Br)/C=C\C=C/C(=C\C=O)C(C)(C)Cc1ccc(Br)cc1</smiles>

$3 e$ $75 \%$ yield, $87 \%$ ee<smiles>Cc1cccc(Br)c1/C(=C\CO)C(C)(C)Cc1ccc(Br)cc1</smiles>
$3 i$

$89 \%$ yield, $54 \%$ ee<smiles>C=C/C=C(\c1ccc(Br)c2cccc(C)c12)C(C)(C)Cc1ccccc1</smiles>
$3 f$ $99 \%$ yield $88 \%$ ee<smiles>CCCc1ccccc1C(=CC=O)C(C)(C#N)CBr</smiles>
3j $99 \%$ yield $95 \%$ ee<smiles>CC(C)(Cc1ccc(Br)cc1)C(=CC=O)C(=CC=O)c1cc2ccccc2c2ccccc12</smiles>
3g $96 \%$ yield $84 \%$ ee<smiles>CC(C)(C)c1ccccc1C(=CC=O)C(C#N)(C#N)Cc1ccccc1</smiles>

3k

$93 \%$ yield, $94 \%$ ee<smiles>CC(C)(Cc1ccc(Br)cc1)C(=CC=O)c1ccc2ccc3cccc4ccc1c2c34</smiles>

3h

99\% yield

$87 \%$ ee

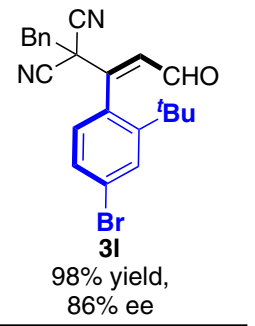

${ }^{\star}$ All reactions were performed by using $\mathbf{1 a}(0.1 \mathrm{mmol}), \mathbf{2 a}-\mathbf{I}\left(0.11 \mathrm{mmol}, 1.1\right.$ equiv), LiOAC $(0.05 \mathrm{mmol})$, catalyst $\mathbf{C 5}(5 \mathrm{~mol} \%)$ and $\mathrm{DCM}(1 \mathrm{ml})$ at $0{ }^{\circ} \mathrm{C}$ for $24 \mathrm{~h}$. †solated yield.

tDetermined by chiral stationary HPLC.

2-iodophenylpropiol-aldehyde $\mathbf{2 a}$ in chloroform $\left(\mathrm{CHCl}_{3}\right)$ at room temperature in the presence of the secondary amine catalyst ${ }^{59-62}$, C1. Despite its high steric hindrance, the desired axially chiral styrene-type 3a was isolated with $74 \%$ yield and complete $Z / E$-selectivity control ( $>20: 1)$, accompanying with moderate enantioselectivity $(65 \%$ ee) (Table 1 , entry 1$)$. This proof-ofprinciple result clearly suggests that the axial chirality of styrenetype compound could be controlled very well by using a chiral secondary amine as organocatalyst. Having thus proven the efficiency of the secondary amine catalyst in our system, we next moved to investigate the substituent and protecting group effects on the catalyst (Table 1, entries 2-7). As shown in Table 1, the electron property on the aromatic ring and the steric size of the silyl ether group have very strong influences on the reactivity and enantioselectivity. Catalyst C5 displayed the best results in terms of the enantioselectivity ( $90 \%$ ee) (Table 1, entry 5). Upon optimizing the reaction conditions through variations of the solvent, temperature, catalyst loading and additive (Table 1, entries 8-13 and Supplementary Tables $1-4)$, we identified the following protocol as optimal: when $\mathbf{1 a}(0.05 \mathrm{mmol})$ was treated with $2 \mathrm{a}(0.055 \mathrm{mmol})$ in the presence of catalyst $\mathbf{C 5}(5 \mathrm{~mol} \%)$ in $\mathrm{DCM}$ at $0{ }^{\circ} \mathrm{C}$ for $24 \mathrm{~h}$ under the addition of LiOAc, the axially chiral styrene-type 3a was obtained in $96 \%$ isolated yield with $94 \%$ ee (Table 1 , entry 13 ).
Substrate scope. After an acceptable optimal reaction condition established, we turn our attention to the substrate scope investigation. Firstly, we have investigated the substituted alkynals and the results were summarized in Table 2. Different substituents $\left(\mathrm{I}, \mathrm{CF}_{3}, \mathrm{SO}_{2} \mathrm{Ph},{ }^{i} \mathrm{Pr},{ }^{t} \mathrm{Bu}\right)$ on the phenyl ring of the alkynal substrates were tolerated to produce the desired axially chiral products with moderate to good results $(\mathbf{3} \mathbf{a}-\mathbf{3 c}, \mathbf{3} \mathbf{j}-\mathbf{3 l})$. Different substituents on the naphthyl rings, such as electrondonating groups $(-\mathrm{OMe})$, electron-neutral and electron-withdrawing groups $(-\mathrm{Br})$, were found to be suitable to give the corresponding products 3d-3f in 75-99\% yields with $87-92 \%$ ee. Moreover, the phenyl group at the substrate 2a could be replaced with 9-phenanthryl or 1-pyrenyl substituent without affecting the chemical yields, albeit with a little bit lower enantioselectivities (3g and $\mathbf{3 h}$ ). It should be pointed out that the aldehyde with two different ortho substituents on the aryl ring is not an appropriate substrate for this transformation under the current standard condition (Table 2, product 3i).

To further explore the scope of this transformation, we then evaluated the use of various diones as nucleophiles (Tables 3, 1c-1n). Most reactions reached completion within $24 \mathrm{~h}$ and gave axially chiral products in moderate to good yields (49-99\%) with excellent enantioselectivities $(90-95 \%$ ee). For the use of substituted benzyl pentanedione substrates, the position and 
Table 3 | The substrate scope with respect to different nucleophiles ${ }^{\star}, \dagger,$.

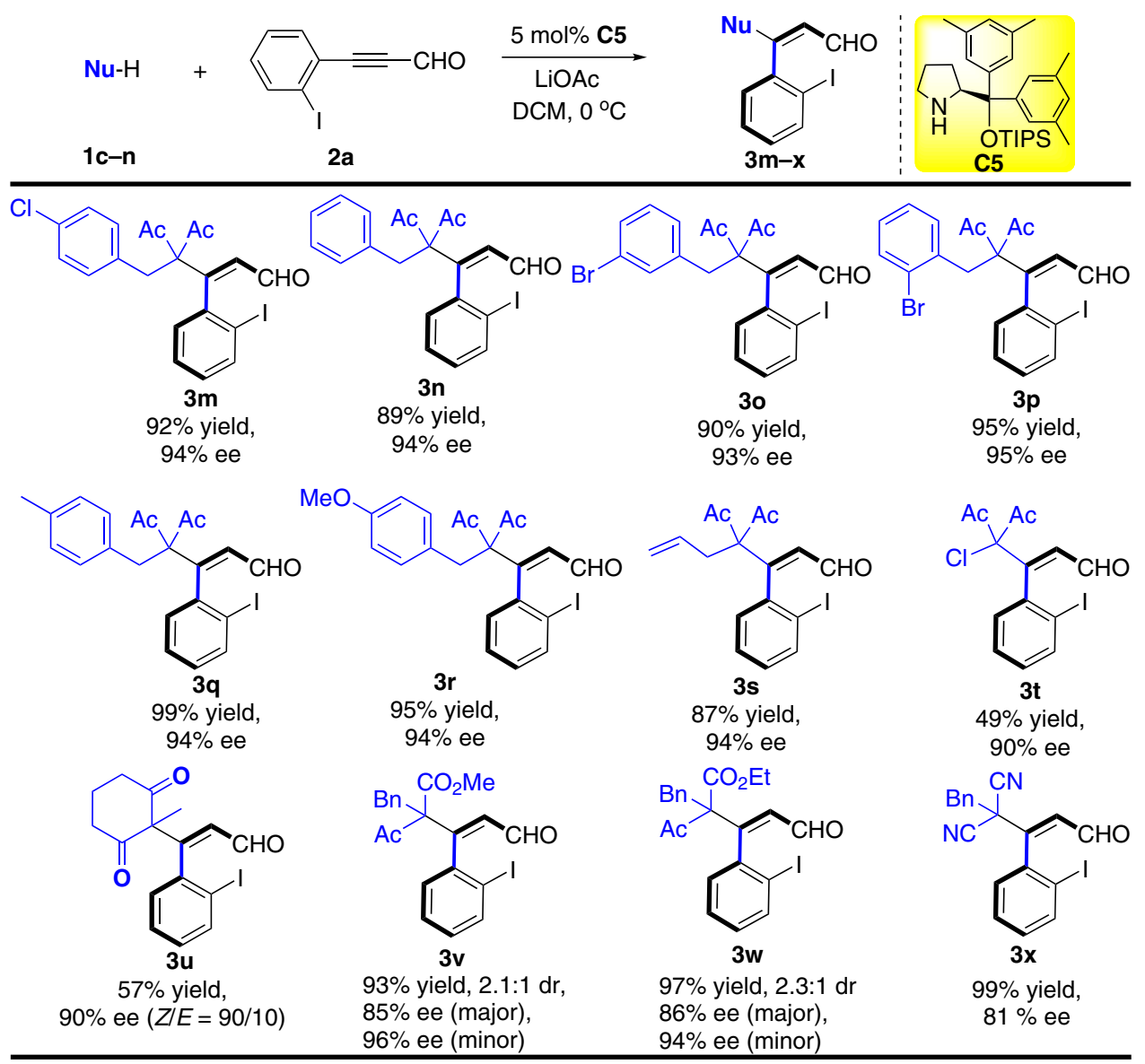

${ }^{\star}$ All reactions were performed by using $\mathbf{1 c}-\mathbf{n}(0.1 \mathrm{mmol}), \mathbf{2 a}\left(0.11 \mathrm{mmol}, 1.1\right.$ equiv), LiOAc $(0.05 \mathrm{mmol})$, catalyst $\mathbf{C 5}(5 \mathrm{~mol} \%)$ and $\mathrm{DCM}(1 \mathrm{ml})$ at $0{ }^{\circ} \mathrm{C}$ for $24 \mathrm{~h}$

a

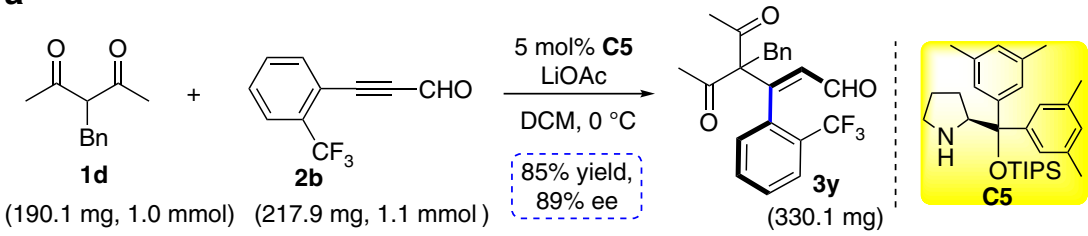

(99\% ee after recrystallization)

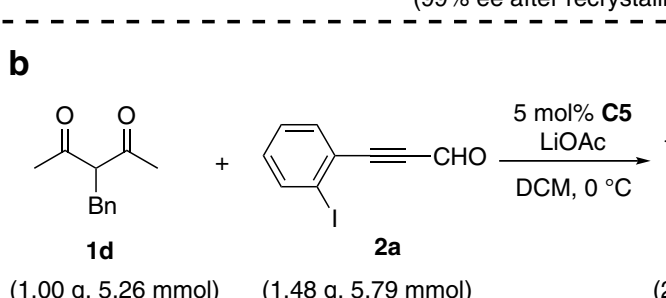

$(330.1 \mathrm{mg})$

Figure $\mathbf{3}$ | Preparative synthesis of $\mathbf{3 y}$ and $\mathbf{3 n}$. (a) Preparative synthesis of $\mathbf{3 y}$ under the corresponding standard conditions. (b) Gram-scale preparation of $\mathbf{3 n}$

electronic properties of substituents $(\mathrm{Ph}, 4-\mathrm{ClPh}, 3-\mathrm{BrPh}$, $4-\mathrm{MePh}, 4-\mathrm{OMePh}$ ) appeared to have a very limited effect on chemical yields and stereoselectivities as expected (Table 3, products 3m-3r). Encouraged by these results, we expanded the generality of the reaction by using 3-allylpentane-2,4-dione, 3-chloropentane-2,4-dione, 2-methylcyclohexane-1,3-dione as reactants (Table 3 , products $3 \mathbf{s}-\mathbf{3 u}$ ). The desired products can be obtained with good enantioselectivities, demonstrating the broad generality of this approach for the synthesis of axially chiral styrene derivatives. To our delight, the reaction performed very well with ketone ester $(\mathbf{1 1}, \mathbf{1} \mathbf{m})$ albeit with unsatisfactory $\mathrm{dr}$ value. Furthermore, we were pleased to find that the reactions 
a

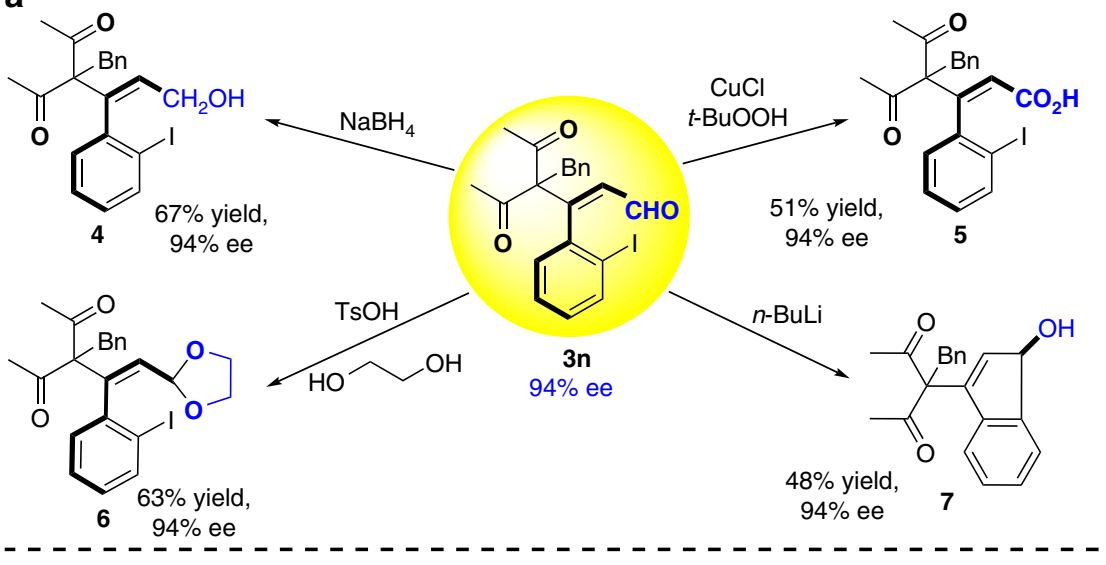

b

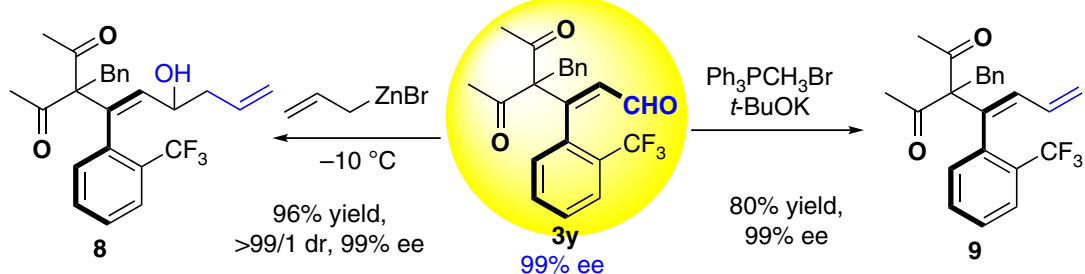

Figure 4 | Versatile chemical transformations of axially chiral 3n and 3y. (a) Synthetic transforamtion of enantioenriched 3n. (b) Synthesis of diene via simple trasformation of $\mathbf{3 y}$.

proceeded smoothly with excellent yields and good enantioselectivities using 2-benzylmalononitrile (1n) as nucleophile (Table 2, 3j-3l; Table 3, 3x).

Preparative scale synthesis of $3 \boldsymbol{n}$ and $3 \boldsymbol{y}$. To demonstrate the utility of this transformation, preparative scale synthesis of products 3n and 3y were carried out. As displayed in Fig. 3, there was almost no change in chemical yield and stereoselectivity. An indication for the configurational stability of the product was obtained by heating a solution of $\mathbf{3 a}$ in dichloroethane (DCE) at $40^{\circ} \mathrm{C}$ for $24 \mathrm{~h}$. HPLC analysis showed that the enantioselectivity was unaffected. Thus, the obtained axially chiral styrene-type compounds may have potential application in asymmetric synthesis. The absolute configuration of 3n was determined to be $S$ by X-ray diffraction analysis (CCDC 1507490, see Supplementary Fig. 5) and those of other products were assigned by analogy.

Synthetic application. With the atroposelective synthesis of axially chiral styrene-type derivatives established, we turned to the demonstration of further synthetic utility through derivatization of the obtained products (Fig. 4). Gratifying, the obtained enal 3n could be selectively reduced to produce alcohol 4 or oxidized to carboxylic acid 5 under mild conditions ${ }^{63,64}$ without any erosion of enantioselectivity. The aldehyde can be protected with glycol and the resulting acetal 6 maintains the axial chirality with same enantioselectivity ${ }^{65}$. Furthermore, by treatment of $\mathbf{3 y}$ with Wittig reagent, the desired 1,3-diene 9 could be easily obtained with the same enantiomeric excess. Thus, the aldehyde group is not necessary for this type of axially chiral compound. It should be worth highlighting that the axial chirality of the styrene can be easily transferred into carbon stereogenic compound 7 under the treatment with $n$-BuLi and the resulting product remains the same enantiomeric excess (Fig. $4 a)^{66}$. Finally, the expected 1,5-diene $\mathbf{8}$ with complete diastereocontrol $(\mathrm{dr}>99: 1)$ was easily achieved by allylation of aldehyde with allylzinc bromide reagent ${ }^{67,68}$, probably providing a new type of axially chiral diene ligand for asymmetric catalysis.

\section{Discussion}

We have developed the first organocatalytic approach to atroposelective synthesis of axially chiral styrene derivatives via direct nucleophilic addition of substituted diones to alkynals. The axially chiral styrene compounds were produced with good chemical yields and enantioselectivities through a secondary amine-catalyzed iminium activation strategy under mild reaction conditions. Moreover, several transformations were investigated to demonstrate synthetic utilities to more functional axially chiral styrene-type compounds. Considering the importance of the axially chiral styrenes, we further anticipate that this promising strategy will motivate the design of other related processes. The application of this strategy to a broader substrate scope and mechanistic investigations are currently underway in our group.

\section{Methods}

General information. Reagents were purchased at the highest commercial quality and used without further purification, unless otherwise stated. Analytical thin layer chromatography (TLC) was performed on precoated silica gel 60 F254 plates. Flash column chromatography was performed using Tsingdao silica gel (60, particle size $0.040-0.063 \mathrm{~mm}$ ). Visualization on TLC was achieved by use of ultraviolet light $(254 \mathrm{~nm})$. NMR spectra were recorded on a Bruker DPX 400 spectrometer at $400 \mathrm{MHz}$ for ${ }^{1} \mathrm{H}$ NMR, $100 \mathrm{MHz}$ for ${ }^{13} \mathrm{C} \mathrm{NMR}$ and $376 \mathrm{MHz}$ for ${ }^{19} \mathrm{~F}$ NMR in $\mathrm{CDCl}_{3}$ or acetone- $d_{6}$ with tetramethylsilane (TMS) as internal standard. Chemical shifts are reported in p.p.m. and coupling constants are given in $\mathrm{Hz}$. Data for ${ }^{1} \mathrm{H}$ NMR are recorded as follows: chemical shift (p.p.m.), multiplicity (s, singlet; $d$, doublet; t, triplet; $q$, quartet; $\mathrm{m}$, multiplet), coupling constant $(\mathrm{Hz})$, integration. Data for ${ }^{13} \mathrm{C}$ NMR are reported in terms of chemical shift ( $\delta$, p.p.m.). Highresolution mass spectra were recorded on a LC-TOF spectrometer (Micromass). Enantiomeric excess was determined on Agilent HPLC using DAICEL CHIRAL column. Racemic compounds were obtained by using diisopropylamine as catalyst. For NMR analysis of the compounds in this article, see Supplementary Figs 6-97. For characterization of structurally-novel chemical compounds, see Supplementary Notes 2 and 3. For the procedure of versatile transformations, see Supplementary Note 4 .

Computational details. For each of the five compounds A-E, a conformational search was first performed using Macromodel (via mixed MCMM/Low-mode sampling method and OPLS_2005 force field). Next, the lowest-energy conformation and the conformations within $3 \mathrm{kcal} \mathrm{mol}^{-1}$ range in energy were used to fully optimize minima and the rotation transition states by density 
functional theory (DFT) method (Supplementary Figs 1-4). Afterward, harmonic vibrational frequency calculations (at $298.15 \mathrm{~K}$ ) were performed to ensure one imaginary frequency for the optimized transition states and no imaginary frequency for the optimized minima. All the optimization and frequency calculations were performed at M06-D3/BS1 level (BS1: 6-31G* basis set for C, H, N, O, F, S Br atoms was used, and Lanl2dz basis set with its ECP were used for I atoms) in gas phase. Single-point energy calculations were performed at M06-D3/BS2 level (BS1I: 6-31 $+\mathrm{G}^{* *}$ basis set for $\mathrm{C}, \mathrm{H}, \mathrm{N}, \mathrm{O}, \mathrm{F}, \mathrm{S}$ Br atoms was used, and Lanl2dz basis set with its ECP were used for I atom, with ultrafine integral grid) by using SMD solvation model (solvent: dichloromethane). For each compound, the lowest-free energy conformation of minimum or transition state was used to discuss the rotation pathway. All the DFT calculations were carried out by Gaussian 09 software package ${ }^{69}$. The $t_{1 / 2}$ values were computed based on transition state theory and first-order kinetic $\left(k=\left(k_{\mathrm{B}} T / h\right)^{*} \operatorname{EXP}(-\Delta G / R T) ; t_{1 / 2}=\ln (2) / k\right)$. The 3D model of each optimized structure was generated with CYL view ${ }^{70}$.

\section{General procedure for atroposelective synthesis of axially chiral styrenes 3 .} (S)-2-bis(3,5-dimethylphenyl)((tri-isopropylsilyloxy)methyl)pyrrolidine $\mathbf{C 5}$ $(5 \mathrm{~mol} \%)$ and $\mathrm{LiOAc}(0.05 \mathrm{mmol})$ were added to a solution of alkynal $2(0.11 \mathrm{mmol}$, 1.1 equiv) in methylene chloride $(1 \mathrm{ml})$. After the mixture was cooled to $0^{\circ} \mathrm{C}$, $1\left(0.10 \mathrm{mmol}, 1.0\right.$ equiv) was added and maintained at $0{ }^{\circ} \mathrm{C}$ for $24 \mathrm{~h}$. After the reaction was complete (monitored by TLC), the mixture was concentrated under reduced pressure and purified by flash chromatography on silica gel and eluted with PE/EA (8/1 to 3/1) to afford the corresponding axially chiral styrene products 3 .

Data availability. The X-ray crystallographic coordinates for structures reported in this article have been deposited at the Cambridge Crystallographic Data Centre (CCDC), under deposition number of CCDC 1507490. These data can be obtained free of charge from The Cambridge Crystallographic Data Centre via http:// www.ccdc.cam.ac.uk/data_request/cif. All other data is available from the authors upon reasonable request.

\section{References}

1. Bringmann, G. et al. Atroposelective synthesis of axially chiral biaryl compounds. Angew. Chem. Int. Ed. 44, 5384-5427 (2005).

2. Kozlowski, M. C., Morgan, B. J. \& Linton, E. C. Total synthesis of chiral biaryl natural products by asymmetric biaryl coupling. Chem. Soc. Rev. 38, 3193-3207 (2009).

3. Bringmann, G., Gulder, T., Gulder, T. A. M. \& Breuning, M. Atroposelective total synthesis of axially chiral biaryl natural products. Chem. Rev. 111, 563-639 (2011).

4. Bencivenni, G. Organocatalytic strategies for the synthesis of axially chiral compounds. Synlett 26, 1915-1922 (2015).

5. Wencel-Delord, J., Panossian, A., Leroux, F. R. \& Colobert, F. Recent advances and new concepts for the synthesis of axially stereoenriched biaryls. Chem. Soc. Rev. 44, 3418-3430 (2015).

6. Loxq, P., Manoury, E., Poli, R., Deydier, E. \& Labande, A. Synthesis of axially chiral biaryl compounds by asymmetric catalytic reactions with transition metals. Coord. Chem. Rev. 308, 131-190 (2016).

7. Uozumi, Y., Matsuura, Y., Arakawa, T. \& Yamada, Y. M. A. Asymmetric Suzuki-Miyaura coupling in water with a chiral palladium catalyst supported on an amphiphilic resin. Angew. Chem. Int. Ed. 48, 2708-2710 (2009).

8. Shen, X., Jones, G. O., Watson, D. A., Bhayana, B. \& Buchwald, S. L. Enantioselective synthesis of axially chiral biaryls by the Pd-catalyzed Suzuki-Miyaura reaction: substrate scope and quantum mechanical investigations. J. Am. Chem. Soc. 132, 11278-11287 (2010).

9. Egami, H., Matsumoto, K., Oguma, T., Kunisu, T. \& Katsuki, T. Enantioenriched synthesis of C1-symmetric BINOLs: iron-catalyzed crosscoupling of 2-naphthols and some mechanistic insight. J. Am. Chem. Soc. 132, 13633-13635 (2010)

10. Yamamoto, T., Akai, Y., Nagata, Y. \& Suginome, M. Highly enantioselective synthesis of axially chiral biarylphosphonates: asymmetric Suzuki-Miyaura coupling using high-molecular-weight, helically chiral polyquinoxaline-based phosphines. Angew. Chem. Int. Ed. 50, 8844-8847 (2011).

11. Li, G.-Q. et al. Organocatalytic aryl-aryl bond formation: an atroposelective $[3,3]$-rearrangement approach to BINAM derivatives. J. Am. Chem. Soc. 135, 7414-7417 (2013).

12. De, C., Pesciaioli, K. F. \& List, B. Catalytic asymmetric benzidine rearrangement. Angew. Chem. Int. Ed. 52, 9293-9295 (2013).

13. Xu, G., Fu, W., Liu, G., Senanayake, C. H. \& Tang, W. Efficient syntheses of Korupensamines A, B and Michellamine B by asymmetric Suzuki-Miyaura coupling reactions. J. Am. Chem. Soc. 136, 570-573 (2014).

14. Link, A. \& Sparr, C. Organocatalytic atroposelective aldol condensation. Synthesis of axially chiral biaryls by arene formation. Angew. Chem. Int. Ed. 53, 5458-5461 (2014)
15. Chen, Y.-H. et al. Atroposelective synthesis of axially chiral biaryldiols via organocatalytic arylation of 2-naphthols. J. Am. Chem. Soc. 137, 15062-15065 (2015).

16. Lotter, D., Neuburger, M., Rickhaus, M., Häussinger, D. \& Sparr, C. Stereoselective arene-forming aldol condensation: synthesis of configurationally stable oligo-1,2-naphthylenes. Angew. Chem. Int. Ed. 55, 2920-2923 (2016).

17. Quinonero, O. et al. Combining organocatalysis with central-to-axial chirality conversion: atroposelective Hantzsch-type synthesis of 4-arylpyridines. Angew. Chem. Int. Ed. 55, 1401-1405 (2016).

18. Moliterno, M. et al. Quinine-catalyzed asymmetric synthesis of 2,2'-binaphthol-type biaryls under mild reaction conditions. Angew. Chem. Int. Ed. 55, 6525-6529 (2016).

19. Gao, H. et al. Practical organocatalytic synthesis of functionalized non-C2symmetrical atropisomeric biaryls. Angew. Chem. Int. Ed. 55, 566-571 (2016).

20. Wang, J.-Z. et al. Symmetry in cascade chirality-transfer processes: a catalytic atroposelective direct arylation approach to BINOL derivatives. J. Am. Chem. Soc. 138, 5202-5205 (2016).

21. Mori, K. et al. Enantioselective synthesis of multisubstituted biaryl skeleton by chiral phosphoric acid catalyzed desymmetrization/kinetic resolution sequence. J. Am. Chem. Soc. 135, 3964-3970 (2013).

22. Barrett, K. T. \& Miller, S. J. Enantioselective synthesis of atropisomeric benzamides through peptide-catalyzed bromination. J. Am. Chem. Soc. 135, 2963-2966 (2013).

23. Ros, A. et al. Dynamic kinetic cross-coupling strategy for the asymmetric synthesis of axially chiral heterobiaryls. J. Am. Chem. Soc. 135, 15730-15733 (2013).

24. Bhat, V., Wang, S., Stoltz, B. M. \& Virgil, S. C. Asymmetric synthesis of QUINAP via dynamic kinetic resolution. J. Am. Chem. Soc. 135, 16829-16832 (2013).

25. Shirakawa, S., Wu, X. \& Maruoka, K. Kinetic resolution of axially chiral 2amino-1,1'-biaryls by phase-transfer-catalyzed $\mathrm{N}$-allylation. Angew. Chem. Int Ed. 52, 14200-14203 (2013).

26. Barrett, K. T., Metrano, A. J., Rablen, P. R. \& Miller, S. J. Spontaneous transfer of chirality in an atropisomerically enriched two-axis system. Nature 509, 71-75 (2014)

27. Cheng, D.-J. et al. Highly enantioselective kinetic resolution of axially chiral BINAM derivatives catalyzed by a Bronsted acid. Angew. Chem. Int. Ed. 53, 3684-3687 (2014).

28. Lu, S., Poh, S. B. \& Zhao, Y. Kinetic resolution of 1,1'-biaryl-2,2'-diols and amino alcohols through NHC-catalyzed atroposelective acylation. Angew. Chem. Int. Ed. 53, 11041-11045 (2014).

29. Armstrong, R. J. \& Smith, M. D. Catalytic enantioselective synthesis of atropisomeric biaryls: a cation-directed nucleophilic aromatic substitution reaction. Angew. Chem. Int. Ed. 53, 12822-12826 (2014).

30. Hazra, C. K., Dherbassy, Q., Wencel-Delord, J. \& Colobert, F. Synthesis of axially chiral biaryls through sulfoxide-directed asymmetric mild C-H activation and dynamic kinetic resolution. Angew. Chem. Int. Ed. 53, 13871-13875 (2014).

31. Ma, Y.-N., Zhang, H.-Y. \& Yang, S.-D. Pd(II)-catalyzed P(O) ${ }^{1} \mathrm{R}^{2}$-directed asymmetric $\mathrm{C}-\mathrm{H}$ activation and dynamic kinetic resolution for the synthesis of chiral biaryl phosphates. Org. Lett. 17, 2034-2037 (2015).

32. Diener, M. E., Metrano, A. J., Kusano, S. \& Miller, S. J. Enantioselective synthesis of 3-arylquinazolin-4(3H)-ones via peptide-catalyzed atroposelective bromination. J. Am. Chem. Soc. 137, 12369-12377 (2015).

33. Miyaji, R., Asano, K. \& Matsubara, S. Bifunctional organocatalysts for the enantioselective synthesis of axially chiral isoquinoline $\mathrm{N}$-oxides. J. Am. Chem. Soc. 137, 6766-6769 (2015).

34. Zheng, J., Cui, W.-J., Zheng, C. \& You, S.-L. Synthesis and application of chiral spiro $\mathrm{Cp}$ ligands in rhodium-catalyzed asymmetric oxidative coupling of biaryl compounds with alkenes. J. Am. Chem. Soc. 138, 5242-5245 (2016).

35. Yu, C., Huang, H., Zhang, Y. \& Wang, W. Dynamic kinetic resolution of biaryl lactones via a chiral bifunctional amine thiourea-catalyzed highly atropo-enantioselective transesterification. J. Am. Chem. Soc. 138, 6956-6959 (2016).

36. Dherbassy, Q. et al. 1,1,1,3,3,3-Hexafluoroisopropanol as a remarkable medium for atroposelective sulfoxide-directed Fujiwara-Moritani reaction with acrylates and styrenes. Chem. Eur. J. 22, 1735-1743 (2016).

37. Zhao, H., Hsu, D. C. \& Carlier, P. R. Memory of chirality. An emerging strategy for asymmetric synthesis. Synthesis 2005, 1-16 (2005).

38. Kumarasamy, E., Raghunathan, R., Sibi, M. P. \& Sivaguru, J. Nonbiaryl and heterobiaryl atropisomers: molecular templates with promise for atropselective chemical transformations. Chem. Rev. 115, 11239-11300 (2015).

39. Kawabata, T., Yahiro, K. \& Fuji, K. Memory of chirality: enantioselective alkylation reactions at an asymmetric carbon adjacent to a carbonyl group. J. Am. Chem. Soc. 113, 9694-9696 (1991).

40. Mori, K., Ohmori, K. \& Suzuki, K. Stereochemical relay via axially chiral styrenes: asymmetric synthesis of the antibiotic TAN-1085. Angew. Chem. Int. Ed. 48, 5633-5637 (2009). 
41. Mori, K., Ohmori, K. \& Suzuki, K. Hydrogen-bond control in axially chiral styrenes: selective synthesis of enantiomerically pure $C_{2}$-symmetric paracyclophanes. Angew. Chem. Int. Ed. 48, 5638-5641 (2009).

42. Yoshimura, T., Tomohara, K. \& Kawabata, T. Asymmetric induction via short-lived chiral enolates with a chiral C-O axis. J. Am. Chem. Soc. 135, 7102-7105 (2013).

43. Baker, R. W., Hambley, T. W., Turner, P. \& Wallace, B. J. Central to axial chirality transfer via double bond migration: asymmetric synthesis and determination of the absolute configuration of axially chiral 1-( $3^{\prime}$-indenyl $)$ naphthalenes. Chem. Commun. 2571-2572 (1996)

44. Hattori, T. et al. Highly stereospecific conversion of $C$-centrochirality of a 3,4-dihydro- $2 H$-1, $1^{\prime}$-binaphthalen-1-ol into axial chirality of a 3,4-dihydro-1,1'-binaphthalene. Tetrahedron Lett. 42, 8035-8038 (2001).

45. Feng, J., Li, B., He, Y. \& Gu, Z. Enantioselective synthesis of atropisomeric vinyl arene compounds by palladium catalysis: a carbene strategy. Angew. Chem. Int. Ed. 55, 2186-2190 (2016).

46. Glorius, F. Chiral olefin ligands-new 'spectators' in asymmetric catalysis. Angew. Chem. Int. Ed. 43, 3364-3366 (2004).

47. Defieber, C., Grützmacher, H. \& Carreira, E. M. Chiral olefins as steering ligands in asymmetric catalysis. Angew. Chem. Int. Ed. 47, 4482-4502 (2008).

48. Tian, P., Dong, H.-Q. \& Lin, G.-Q. Rhodium-catalyzed asymmetric arylation. ACS Catal. 2, 95-119 (2012).

49. Erkkilä, A., Majander, I. \& Pihko, P. M. Iminium catalysis. Chem. Rev. 107, 5416-5470 (2007).

50. Brazier, J. B. \& Tomkinson, N. C. Secondary and primary amine catalysts for iminium catalysis. Top. Curr. Chem. 291, 281-347 (2009).

51. Fraile, A., Parra, A., Tortosa, M. \& Alemán, J. Organocatalytic transformations of alkynals, alkynones, propiolates, and related electron-deficient alkynes. Tetrahedron 70, 9145-9173 (2014).

52. Jones, S. B., Simmons, B. \& MacMillan, D. W. C. Nine-step enantioselective total synthesis of (+)-minfiensine. J. Am. Chem. Soc. 131, 13606-13607 (2009).

53. Zhang, X.-S., Zhang, S.-L. \& Wang, W. Iminium-allenamine cascade catalysis: one-pot access to chiral $4 \mathrm{H}$-chromenes by a highly enantioselective Michael-Michael sequence. Angew. Chem. Int. Ed. 49, 1481-1484 (2010).

54. Liu, C., Zhang, X.-S., Wang, R. \& Wang, W. 'One-pot' access to 4 H-chromenes with formation of a chiral quaternary stereogenic center by a highly enantioselective iminium-allenamine involved oxa-Michael-aldol cascade. Org. Lett. 12, 4948-4951 (2010).

55. Alemán, J. et al. Asymmetric synthesis of 4-amino-4H-chromenes by organocatalytic oxa-Michael/aza-Baylis-Hillman tandem reactions. Chem. Eur. J. 16, 9453-9456 (2010).

56. Zhang, X. et al. An organocatalytic cascade approach toward polysubstituted quinolines and chiral 1,4-dihydroquinolines-unanticipated effect of N-protecting groups. Angew. Chem. Int. Ed. 51, 7282-7286 (2012).

57. Fang, Z.-J. et al. Asymmetric synthesis of axially chiral isoquinolones: nickel-catalyzed denitrogenative transannulation. Angew. Chem. Int. Ed. 54, 9528-9532 (2015)

58. Zhang, J.-W. et al. Discovery and enantiocontrol of axially chiral urazoles via organocatalytic tyrosine click reaction. Nat. Commun. 7, 10677 (2016).

59. Marigo, M., Wabnitz, T. C., Fielenbach, D. \& Jørgensen, K. A. Enantioselective organo-catalyzed $\alpha$ sulfenylation of aldehydes. Angew. Chem. Int. Ed. 44, 794-797 (2005)

60. Hayashi, Y., Gotoh, H., Hayashi, T. \& Shoji, M. Diphenylprolinol silyl ethers as efficient organocatalysts for the asymmetric Michael reaction of aldehydes and nitroalkenes. Angew. Chem. Int. Ed. 44, 4212-4215 (2005).

61. Jensen, K. L., Dickmeiss, G., Jiang, H., Albrecht, Ł. \& Jørgensen, K. A. The diarylprolinol silyl ether system: a general organocatalyst. Acc. Chem. Res. 45, 248-264 (2012)

62. Meninno, S. \& Lattanzi, A. Asymmetric organocatalysis mediated by $\alpha$, $\alpha$-L-diaryl prolinols: recent advances. Chem. Commun. 49, 3821-3832 (2013).
63. Liu, J. et al. A convenient synthesis of $(R)$-salmeterol via Rh-catalyzed asymmetric transfer hydrogenation. Tetrahedron Asymmetry 19, 1824-1828 (2008).

64. Mannam, S. \& Sekar, G. CuCl catalyzed oxidation of aldehydes to carboxylic acids with aqueous tert-butyl hydroperoxide under mild conditions. Tetrahedron Lett. 49, 1083-1086 (2008).

65. Xie, Y. \& Floreancig, P. E. Stereoselective heterocycle synthesis through a reversible allylic alcohol transposition and nucleophilic addition sequence. Chem. Sci. 2, 2423-2427 (2011).

66. Garcia-Yebra, C., Janssen, J. P., Rominger, F. \& Helmchen, G. Asymmetric iridium(I)-catalyzed allylic alkylation of monosubstituted allylic substrates with phosphinooxazolines as ligands. Isolation, characterization, and reactivity of chiral (allyl)iridium(III) complexes. Organometallics 23, 5459-5470 (2004).

67. Kahnberg, P., Lee, C. W., Grubbs, R. H. \& Sterner, O. Alternative routes to pterulone. Tetrahedron 58, 5203-5208 (2002).

68. Sada, M., Ueno, S., Asano, K., Nomura, K. \& Matsubara, S. Stereoselective preparation of 3-alkanoylprop-2-en-1-ol derivatives. Synlett 2009, 724-726 (2009).

69. Frisch, M. J. et al. Gaussian, 09, Revision C.01 (Gaussian, Inc., 2009).

70. Legault, C. Y. CYLview, $1.0 b$ (Université de Sherbrooke, 2009). Available at: http://www.cylview.org.

\section{Acknowledgements}

We are thankful for the financial support from the National Natural Science Foundation of China (No. 21572095), Shenzhen special funds for the development of biomedicine, internet, new energy and new material industries (JCYJ20150430160022510). B.T. thanks the Thousand Young Talents Programme for financial support. B.T. sincerely dedicated this paper to professor Carlos F. Barbas III for a deep memory.

\section{Author contributions}

S.-C.Z. performed most of experiments. S.W. took part in the reaction development and synthesized several products. L.Y. helped with characterizing all new compounds. Q.Z. and L.W.C. did the computational studies. B.T. conceived and directed the project and wrote the paper.

\section{Additional information}

Supplementary Information accompanies this paper at http://www.nature.com/ naturecommunication

Competing interests: The authors declare no competing financial interests.

Reprints and permission information is available online at http://npg.nature.com/ reprintsandpermissions/

How to cite this article: Zheng, S.-C. et al. Organocatalytic atroposelective synthesis of axially chiral styrenes. Nat. Commun. 8, 15238 doi: 10.1038/ncomms15238 (2017).

Publisher's note: Springer Nature remains neutral with regard to jurisdictional claims in published maps and institutional affiliations.

This work is licensed under a Creative Commons Attribution 4.0 International License. The images or other third party material in this article are included in the article's Creative Commons license, unless indicated otherwise in the credit line; if the material is not included under the Creative Commons license, users will need to obtain permission from the license holder to reproduce the material. To view a copy of this license, visit http://creativecommons.org/licenses/by/4.0/

(C) The Author(s) 2017 


\title{
Erratum: Organocatalytic atroposelective synthesis of axially chiral styrenes
}

\author{
Sheng-Cai Zheng, San Wu, Qinghai Zhou, Lung Wa Chung, Liu Ye \& Bin Tan
}

Nature Communications 8:15238 doi: 10.1038/ncomms15238 (2017); Published 3 May 2017; Updated 27 Jun 2017

An incorrect version of the Supplementary Information was inadvertently published with this Article. The HTML has now been updated to include the correct version of the Supplementary Information.

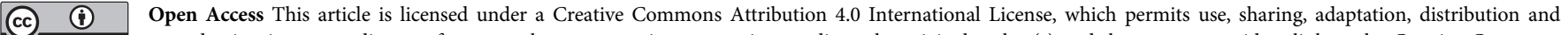
reproduction in any medium or format, as long as you give appropriate credit to the original author(s) and the source, provide a link to the Creative Commons license, and indicate if changes were made. The images or other third party material in this article are included in the article's Creative Commons license, unless indicated otherwise in

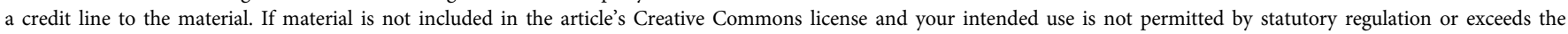
permitted use, you will need to obtain permission directly from the copyright holder. To view a copy of this license, visit http://creativecommons.org/licenses/by/4.0/

(C) The Author(s) 2017 